\title{
Factors Influencing Digital Marketing and Digital Payment on Consumer Purchase Behaviour
}

\author{
Monica Tiewul
}

Coburg University of Applied Sciences and Arts, Germany

\begin{abstract}
ARTICLE INFO

\begin{tabular}{l}
\hline Keywords: \\
Digital \\
Financial \\
Innovation \\
Money \\
Technology
\end{tabular}

ABSTRACT

The issue of whether innovation and technological advancement continually bring new phenomenon remains unpredictable, especially in the financial industry. As technology and digital services continue to ingrain themselves into more aspects of lives, the financial sector has not been immuned. New technology has given way to new services and with new services comes the gradual disruption of the old. This study researched on the influence of digital marketing and digital payment on consumer purchase behaviour in Coburg, Germany. The availability of digital marketing is enabling many companies of all sizes to embrace mobile and data while adopting a 'cloud first' approach to redesigning their business models. This brings about the introduction of a new 'pay-as-you-go' business model that enables efficiency, low-cost speed to scale and creation of new, richer customer experience. This research sort to examine the impact of digital marketing on consumer purchase behaviour, assess the factors influencing consumer to patronise digital payment and examine the future of digital payment methods. In this research, primary and secondary data are utilised. The data has been analysed using descriptive and multivariate statistical methods like factor loading analysis, correlation, cross tabulation, and chi-square. From this research, it is concluded that the availability of extensive information, variety of products, level of satisfaction and level of education are the most essential factors influencing digital marketing and digital payment and this will lead to an increase in the digital payment methods with more security in the future. Also, bitcoin will not be accepted as a future digital payment method.
\end{abstract}

\section{Introduction}

The advent of the internet and business digitalization in recent years has necessitated a rethinking of marketing strategies and most importantly, the consumer purchase behaviour by giving individual access to world-wide content, means to generate content, access to distribution infrastructure for user-generated content and access to audience. The internet has had a huge impact on communication, sharing of information and knowledge, and has also encouraged personal creativity and innovation.

Digitalization is a major trend in societies and businesses today and in the future. The world has advanced so much that the economy has become digital economy, and today multi-channel delivery is crucial for every business. Customers progress from choosing purchases and making payments to undertaking seamless customer-driven interactions via mobile devices.

According to Parviainen et al., 2017, digitalization is seen as a more fundamental change than just digitizing existing processes or work products. In the work of Brennen \& Kreiss, 2014, digitalization refers to "the adoption or increase in use of digital or computer technology by an organization, industry, country, etc."

\footnotetext{
* Corresponding author E-mail address: monicatiewul@ gmail.com 
Digital marketing is a marketing tool to promote products on online platform (s). The rise of digital marketing nowadays is alarming and more efficient as people use digital device instead of going to shops to do purchase. Digital marketing industry in Germany covers almost all the business sectors. The power of digital marketing allows geophysical barriers to disappear making all consumers and businesses across the globe potential customers and suppliers.

Society is becoming paperless. In Braga et al. (2013), money as a means of payment has also evolved along history. In the past decades, it has become less physical but more digital. It seems "money's destiny is to become digital" (OCDE, 2002, p.7). The increase in digital payment methods also increases more digital marketing which brings about less interest in holding paper or coin money.

The growth of entrepreneurship in Bavaria, Germany has led to an increase in digital marketing and payment in the region and the whole country at large. Thanks to entrepreneurship, the digital marketing and digital payment sectors or companies play a key role in the economic development and contributes to a large extent, employment.

Despite all the advantages of the digital environment and e-commerce, the internet has also given consumers easier access to illegal content and made distribution easier for sellers (Gentry et al., 2006). Illegal content includes anything from counterfeit products through illegal sale of copyrighted products (non-licensed copyrighted material such as books, films, music) and counterfeit goods (i.e. copies of patented goods).

Curiosity about the rapid growth of the digital marketing and digital payment in Bavaria and how it has influenced the consumer purchase behaviour is what has influenced the decision to conduct this research. Therefore, the research sort to examine the impact of digital marketing on consumer purchase behaviour, assess the factors influencing consumer to patronise Digital Payment (DP) and to examine the future of digital payment methods. Also, the hypothesis of the work probed the question: Is there a possibility of introducing and accepting cybercurrencies like Bitcoin as future digital payment especially in Germany?

\section{Methodology}

Primary data was collected directly from respondents using administered questionnaire. This method is considered the most effective and detailed form of getting reliable information for analysis. Sample of 60 participants were covered in this primary data collection. Data from journals, books, magazines, and other articles served as secondary sources.

A non-probabilistic sampling and probability sampling has been used in selecting the sample. In the non-probability sampling, purposive sampling was used. Samples were chosen because they fulfilled certain criteria. In the probability sampling, simple random sampling was used. The simple random sampling was used because all the respondents have an equal opportunity or chance of being selected. The respondents were chosen by distributing questionnaire randomly out to people who fell within the targeted group.

Assessing the factors influencing consumers to patronise digital payment has been measured with a Likert-type instrument consisting of 6 items with performance factor loading analysis. Correlation was used to determine the relationship between the future digital payment and its security. Cross-tabulation and chi-square were used to show the relationship between acceptance of bitcoin and the adverse effect on the financial system.

\section{Results and Discussion of Findings}

On the examination of the impact of digital marketing on the consumer purchase behaviour in today's era, the findings from the study established that majority of consumers spent much time per day on the digital platforms to buy goods. Technology has become part of everybody such that in every minute and second, one must check out what is happening online. This goes in line with a study conducted by Fritz et al. (2017) indicating that mobile technologies have 
become a substantial part of lives. Figure 1 represents results of the impact or influence of the digital marketing on the consumer purchase behaviour. The most influencing factor of digital marketing on consumer purchase behaviour is availability of extensive information with a percentage of 28.3. Ambati (2017) conducted a study on digital marketing and found that people use digital devices instead of visiting physical shops and that digital marketing campaigns are becoming more prevalent and more efficient. However, this finding contrast that of Girshwyn (2016) who conducted a research on digital marketing impact on the consumer decision making process and found that post purchase behaviour is the most influential factor.
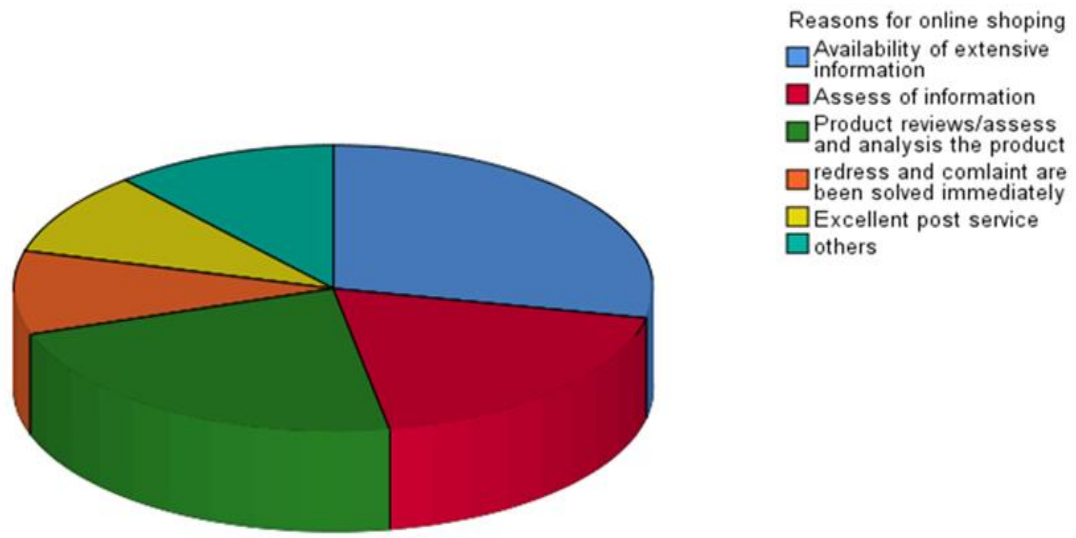

Figure 1: Influence of the digital marketing on consumer purchase behaviour Source: (Field Data Tiewul, 2020)

The analysis of factors influencing consumer to patronise Digital Payment (DP) shows that majority of the consumers prefer digital payment very often. This result falls in line with the work of Grass \& Weber (2016) on the debate on digitalisation and the labour market in Europe. They found that Germany is a strong society of digitalisation but still with room for improvement with regular internet use of $84 \%$, basic digital skills of $66 \%$ and poor digital skills $20 \%$ of the employable population.

Consumers also prefer to buy some kinds of product through digital payment. These products include electronic product, food product, shopping products (clothes) and daily news. Data from this study found that majority prefer electronic products like laptops, phones, E-books, computer, tickets, car, printer, among others. This is consistent with the study of Yasau (2015) on the impact of digital technology on consumer purchase behaviour.

Various payment methods/modes in which consumers can make DP include mobile payment, giving bank details, credit/debit card, bitcoin, among others. The findings of this study show that most consumers make DP using mobile payments platforms such as Goggle Pay, PayPal, Apple Pal, Samsung Pal and what have you. Mobile payment is a thing of the present, which is possible for anyone owning a mobile phone. This agrees with the findings of Braga et al. (2013) which revealed that digital method /mode has become a trend.

The factor influencing the consumer to patronise the digital payment are variety of products, low price, provides offers/rewards for payment, various payment mode, detailed charges information and cancelling, return of purchase guaranteed, among others. Factor loading of the other factors influencing consumer to patronise DP is obtained by performing factor analysis. It is indicated that level of satisfaction is the most efficient and significant factor influencing consumer to patronise DP. Table 1 shows the factor loadings of the factors influencing consumer to patronise DP.

Table 1.

Factor Loading of Items of the Factors influencing Consumer to patronise Digital Payment (DP) 


\begin{tabular}{clc}
\hline Factors & Description of scale items & Factor Loading \\
\hline 1 & Level of satisfaction & 0.832 \\
2 & Marital status & 0.765 \\
3 & Level of education & 0.713 \\
4 & Monthly income & 0.666 \\
5 & Frequency of purchase & 0.641 \\
6 & Time/day online & 0.483 \\
\hline
\end{tabular}

Source: (Field Data Tiewul, 2020)

From table 1, 0.832 representing level of satisfaction is the most efficient and significant factor influencing consumer to patronise DP. The percentage of respondent's level of satisfaction with DP has been very great. Majority of the respondents, $52.8 \%$ are satisfied with DP whereas $32.1 \%$ of respondents were very satisfied. The factor analysis is followed by marital status, 0.765. From statistics, $88.7 \%$ were singles while $11.3 \%$ were married. Respondents that are single mostly patronise DP than married respondents. This is further followed by level of education with factor loading of 0.713 , monthly income, 0.666 and the rest that follow still have less factor influencing consumers to patronise DP that is, frequency of purchase and time/day online with 0.641 and 0.483 respectively.

The mean scores, table 2, of the four factors influencing consumer to patronise DP are level of satisfaction, marital status, level of education and monthly income. While the level of satisfaction and marital status respectively led in the factor loading analysis, they are within the less important range when considering the major influential factors on consumer to patronise DP using the standard deviation figures. Crowe et al. (2006) discovered that consumer's decision concerning payment choice is quite complex.

Table 2.

Mean and standard deviation of major factors influencing consumer to patronise DP

\begin{tabular}{lcc}
\hline Description of scale items & Mean & Standard Deviation \\
\hline Level of satisfaction & 1.85 & 0.718 \\
Marital status & 1.11 & 0.320 \\
Level of Education & 2.49 & 1.031 \\
Monthly income & 1.70 & 0.774 \\
\hline
\end{tabular}

Source: (Field Data Tiewul, 2020)

With increase of future digital payment, it turned out that $81.1 \%$ of the respondents agreed that there will be a positive increase in the digital payment in the future while $13.2 \%$ of respondents disagreed on the increase of future digital payment while $5.7 \%$ respondents were neutral about the future of digital payment. It can therefore, be said that there will be a positive increase in digital payment in the future. However, as high as $47.2 \%$ of the respondents were sceptical about the reasons for the increase of digital payment in the future. While $37.7 \%$ were of the view that digital payment will be easy going with fast processes, $15.1 \%$ rather saw that DP in the future will be more convenient than today and hence lead to less cash in the economy. This is at parallel with the work of Labrecque, (2013) who discovered that technological evolution role in development rather influenced the shift in power from marketer to consumer.

Security in digital payment is very important to the customers as well as to the efficient development of the financial sector. It is not surprising that respondents were so particular about the security of the future of DP. Majority of the respondents, $66 \%$ agreed on the fact that the future of DP should be more secured than today, while $26.4 \%$ were uncertain about the security of the future DP. With $7.5 \%$ of respondents disagreeing that the future security will be more secured than today. Interestingly, as much as $35.9 \%$ of the respondents reasoned that the security of DP in the future will be more technologically advanced due to more sophisticated and well-equipped infrastructure. Some respondents, 9.4\% were however, of the 
view that there could be increase in cybersecurity in the future. But $54.7 \%$ of the respondents had no idea about the security of future DP and indicated that the future is unknown and sometimes cannot be predicted.

The relationship between increase in future digital payment and its security was determined by correlation. The findings are presented in Table 3. From Table 3, with 53 respondents, there is a positive correlation between the increase of DP and its security in the future with a Pearson correlation of 0.041 and a significance (2-tailed) of 0.771 . Therefore, an increase in the DP in the future will lead to a significant increase in future security of DP.

Table 3.

Correlation of DP and the Security of DP in the future

\begin{tabular}{llcc}
\hline & \multicolumn{1}{l}{ Future DP will increase } & Security of future DP \\
\hline Future DP will increase & $\mathrm{r}$ & 1 & 0.041 \\
Security of future DP & $\mathrm{r}$ & 0.041 & 1 \\
Number & 53 & & 53 \\
\hline
\end{tabular}

Source: (Field Data Tiewul, 2020)

\subsection{Hypothesis Testing}

If the acceptance of bitcoin will have adverse effects on the financial system and as a future digital payment especially in Germany. To answer this hypothesis, Chi-square statistical technique was used. The hypothesis test is written below, and decision rule is set at an alpha level of $0.05(\alpha=0.05)$.

- H0: The acceptance of bitcoin has no adverse effect on the financial system and as a future digital payment especially in Germany

- H1: The acceptance of bitcoin has an adverse effect on the financial system and as a future digital payment, especially in Germany.

The cross tabulation, Table 4 shows that out of the 11 respondents who believed that bitcoin will not lead to a national and global financial issue, $72.7 \%$ of them are of the view that it is likely to cause depreciation in the economy whereas $18.2 \%$ were neutral on the view that accepting bitcoin will lead to national and global financial issues or it will have no effect on the economy. The remaining $9.1 \%$ of the respondents agreed to the view that accepting bitcoin will lead to national and global financial issues. In the case of agreeing that bitcoin acceptance will lead to national and global financial issues, $45 \%$ of the respondents disagreed, $35 \%$ were neutral on the issue whilst $20 \%$ thought otherwise with the view that bitcoin acceptance will have a financial issues and effect on the economy.

Table 4.

Cross-tabulation showing relationship between acceptance of bitcoin and the adverse effect on the financial system

\begin{tabular}{llllll}
\hline & \multicolumn{5}{c}{ Bitcoin used as a future digital payment } \\
\cline { 2 - 6 } Acceptance of bitcoin will & Count/\% & Disagree & Neutral & Agree & Total \\
lead to national and global & Disagree & $8 / 72.7 \%$ & $2 / 18.2 \%$ & $1 / 9.1 \%$ & $11 / 100 \%$ \\
financial issues (\%) & Neutral & $13 / 59 \%$ & $8 / 36.4 \%$ & $1 / 4.5 \%$ & $22 / 100 \%$ \\
& Agree & $9 / 45.0 \%$ & $7 / 35.0 \%$ & $4 / 20.0 \%$ & $20 / 100 \%$ \\
\hline
\end{tabular}

Source: (Field Data Tiewul, 2020)

The chi-square test for this distribution, Table 5, produced a p-value (Aysmp. Significant) of 0.390 which is greater than 0.05 . There is therefore, statistically insignificant evidence at $\alpha=0.05$ to show that the null hypothesis is true. Conclusively, the variables are independent of 
each other and hence there is no statistical relationship between the acceptance of bitcoin as a future digital payment and its adverse effect on the financial system, especially in Germany.

Table 5.

Chi-Square Test chi-square showing the relationship between acceptance of bitcoin and the adverse effect on the financial system, especially in Germany

\begin{tabular}{lccc} 
& Value & Df & Asymptotic sig. (2-sided) \\
\hline Person chi-square & 4.118 & 4 & 0.390 \\
Likelihood Ratio & 4.246 & 4 & 0.374 \\
Linear-by-Linear Association & 2.591 & 1 & 0.107 \\
No. of valid cases & 53 & &
\end{tabular}

a. 4 cells $(44.4 \%)$ have expected count less than 5 . The minimum expected count is 1.25 .

Source: (Field Data Tiewul, 2020)

\section{Conclusion}

The availability of extensive information, access to information, product reviews and analysis, the immediacy of redress of complaints and excellent postal services are the major driving factors impacting the consumer purchase behaviour on digital marketing. Essentially, the most influential factor discovered in this research is the availability of extensive information to consumers. This influences them to always go online to search for information to satisfy their curiosity and as such more information about similar products always pop up daily for the consumer to continue to search.

With the analysis of factors influencing consumer to patronise digital payment, it can be stated from this research that majority of consumers prefer digital payment. The variety of products on digital payment is the major factor that influences the consumer to patronise the digital payment.

Of the other factors, the level of satisfaction obtained by factor loadings analysis stood as the most influential factor just as the level of education with the highest mean score.

It can, therefore, be stated that there is a positive correlation between DP and its security in the future. This means with an increase in future DP, there will be a significant increase in security of DP. In the future, bitcoin is likely not to be accepted as a digital payment method.

In conclusion, the availability of extensive information, varieties of products, level of satisfaction and level of education are the most essential factors influencing digital marketing and digital payment, especially in Germany.

\section{Acknowledgment}

Applause and thanks to KAAD and the Dioceses of Münster for the scholarship and the unconditional support for my studies in Germany.

\section{References}

Ambati Y. (2017) Digital Marketing. International Journal of Research in management ISSN 2250-057X Pg 9-14.

Baddeley M. (2004). Using e-cash in the new economy: An economic analysis of micropayment systems. J. Electron. Commerce Res., vol. 5, no. 4, pp. 239-253. [Online]. Available: http://web.csulb.edu/journals/jecr/issues/20044/Paper3.pdf

Braga F.D.A., Giuliana I. and Mazzon J.A. (2013) Do Digital Wallets as a Payment Method influence consumer in their Buying Behaviour? XXXVII Encontro da ANPAD

Brennen S. and Kreiss D. (2014). Digitalization and Digitization [Online]. Available: http://culturedigitally.org/2014/09/digitalization-and-digitization/ 
Crowe M. Schuh S. and Stavins J. (2006). Consumer Behaviour \& Payment Choice: A Conference Summary. No.06-1 Federal Reserve Bank of Boston. http://www.bos.frb.org/economic/ppdp/index.htm.

Fritz W., Sohn S. \& Seegebarth B. (2017) Broadening the perspective on Mobile Marketing. Psychology and marketing. Vol 34(2): 112-118 (February 2017)

Gentry J.W., Putrevu S \& Shultz II C.J. (2006) The effect of counterfeiting on consumer search. Journal of Consumer Behaviour, Vol. 5, Iss. 3, pp. 245 - 256.

Grass K. \& Weber E. (2016) The Debate on Digitalisation and the labour market in Europe. Institute for Employment Research ISSN 2195-2663. IAB- Discussion paper 39/2016

Girshwyn R. (2016). Digital Marketing impact on the consumer decision making process in Nike's customer retail operations in South Africa. Gordon Institute of Business Science. University of Pretoria.

Jain S.C. (1999). Marketing Planning and Strategy. 6th Edition South-Western Collage Publication ISBN 0-324-012480-5.pg 2 \&107

Krishna K.M. (2018). Influence of Digital Marketing on Consumer Purchase Behaviour. International Journal of Trend in Scientific Research and Development (IJTSRD) No 24566470 Vol-3/issue-1/Nov-Dec 2018 www.ijtsrd.com

Labrecque L. I. (2013). Consumer Power: Evolution in the Digital Age. Journal of Interactive Marketing 27(2013) 257-269 www.eleevier. com/locate/intmar.

Luther J.W. (2016). Bitcoin and the future of Digital Payment. Published by: Independent Institute https://www.jstor.org/stable/24562161.

Organization for Economic Co-Operation and Development (OCDE) (2002). The Future of the Money. Report, pp. 11-30.

Parviainen P., Tihinen M., Kääriäinen J., Teppola S. (2017). Tackling the digitalization challenge: how to benefit from digitalization in practice. ISSN (online):2182-7788

Papadopoulos G. (2005). Blockchain and Digital Payments: An Institutionalist Analysis of Cryptocurrencies: chapter 7. https://doi.org/10.1016/B978-0-12-802117-0.00007-2 Assessed on 03.01.2020

Srivastava J. and Raghubir P. (2008). Monopoly Money: the effect of payment coupling and form on spending behavior. Journal of Experiential Psychology Applied. 14(3), pp. 213225.

Soman D. (2001). Effects of payment mechanism on spending behavior: the role of rehearsal and immediacy of payments. Journal of Consumer Research, 27(4), pp. 460-474.

Soman, D. (2003). The effect of payment transparency on consumption: quasi-experiments from the field. Marketing Letters, 14(3) pp. 173-183.

Yasau S. (2015) The impact of Digital Technology on Consumer Purchase Behaviour. The Journal of Financial Perspectives: FinTech Winter 2015/Vol. 3, Iss. 3. 